\title{
IMUNIZAÇÃO CONTRA A HEPATITE B E OS ACIDENTES OCUPACIONAIS: IMPORTÂNCIA DO CONHECIMENTO NA ODONTOLOGIA
}

\section{Artênio José Isper Garbin}

Docente Adjunto do Programa de Pós-Graduação em Odontologia Preventiva e Social, Faculdade de Odontologia de Araçatuba da Universidade Estadual Paulista (UNESP), Araçatuba (SP), Brasil.

\section{Bruno Wakayama}

Mestrando do Programa de Pós-Graduação em Odontologia Preventiva e Social, Faculdade de Odontologia de Araçatuba da Universidade Estadual Paulista (UNESP), Araçatuba (SP), Brasil.

E-mail: brunowakayama@gmail.com

\section{Mariana Martins Ortega}

Mestranda do Programa de Pós-Graduação em Odontologia Preventiva e Social, Faculdade de Odontologia de Araçatuba da Universidade Estadual Paulista (UNESP), Araçatuba (SP), Brasil.

\section{Cléa Adas Saliba Garbin}

Docente titular do Programa de Pós-Graduação em Odontologia Preventiva e Social, Faculdade de Odontologia de Araçatuba da Universidade Estadual Paulista (UNESP), Araçatuba (SP), Brasil.
RESUMO: A prática odontológica está diretamente ligada às várias fontes de contaminação com o vírus da hepatite $\mathrm{B}$, portanto medidas protetivas são necessárias a fim de evitar sua infecção. O objetivo do estudo foi avaliar a conduta dos acadêmicos frente ao protocolo de vacinação contra a hepatite $B$ e sua atitude pós-acidentes perfurocortantes. Trata-se de um estudo transversal descritivo quantitativo, com 153 acadêmicos de odontologia de uma universidade pública do noroeste paulista. Para análise dos dados, utilizou-se o software Epi. Info 7.1, por meio da estatística descritiva. Observou-se que 92,16\% dos alunos afirmaram ter sido imunizados com a vacina, entretanto, $73,1 \%$ destes não fizeram o exame anti-HBS. Em relação aos acidentes ocupacionais, $18,3 \%$ dos indivíduos já se feriram, e apenas 28,6\% fizeram os exames com a frequência recomendada. Conclui-se que há falhas nas condutas e atitudes dos alunos sobre os temas abordados, necessitando de discussões sobre as medidas preventivas e protetivas a fim de torná-las mais seguras e eficazes em sua rotina de trabalho.

PALAVRAS-CHAVE: Condutas na prática dos dentistas; Estudantes de odontologia; Exposição ocupacional; Hepatite B; Vacina conta hepatite B.

\section{IMMUNIZATION AGAINST HEPATITIS B AND OCCUPATIONAL ACCIDENTS: IMPORTANCE OF INFORMATION IN DENTISTRY}

\begin{abstract}
The dentist practice is directly linked to several contamination sources such as Hepatitis B virus and prevention is required for its avoidance. Current study evaluates the behavior of dentistry students for vaccine protocol against Hepatitis B and their attitudes after perforating accidents. Current transversal, descriptive and quantitative study comprises 153 dentistry students of a public university in the northwestern region of São Paulo, Brazil. Data were analyzed with Epi.Info 7.1 by descriptive statistics. Results show that 92.16\% of students had been immunized but $73.1 \%$ did not undergo the anti-HBS test; $18.3 \%$ were perforated and only $28.6 \%$ submitted to tests with the recommended frequency. There are faults in students' behavior and attitudes on the themes analyzed. Further discussions are required on preventive and protection measures for better and more efficacious work routine.
\end{abstract}

KEY WORDS: Hepatitis B; Vaccine against Hepatitis B; Occupational exposure; Behavior in dentists' practice; students of Dentistry. 


\section{INTRODUÇÃO}

A hepatite, segundo a Organização Mundial da Saúde (OMS), é uma doença pandêmica, em que 1,4 milhões de pessoas morrem por ano, sendo cerca de $47 \%$ destes, em decorrência do vírus da hepatite $\mathrm{B}$ (VHB). Dada a dimensão epidemiológica envolvendo as doenças hepáticas, foram criadas diretrizes e recomendações pela OMS em 2015, a fim de alertar a sociedade dos riscos da infecção, a importância da prevenção e a necessidade de implantação de políticas públicas voltadas a esse agravo, que assolam principalmente os indivíduos de baixas e médias rendas e que vivem nos países africanos e asiáticos (OMS, 2015).

A prevenção da infecção pelo vírus da hepatite B é amplamente pautada pelas instituições internacionais e nacionais, devido aos grandes agravos que podem repercutir a vida humana, evoluindo nos casos mais graves, para o quadro clínico de cirrose e câncer de fígado (MINISTÉRIO DA SAÚDE, 2015). De acordo com dados epidemiológicos, os profissionais da área da saúde apresentam as taxas de prevalência da infecção pelo VHB maiores que a da população em geral (MINISTÉRIO DA SAÚDE, 2009), em detrimento da exposição laboral e dos riscos de acidentes envolvendo as várias fontes de contaminação e infecção pelo vírus. Nesta situação os profissionais da odontologia, incluindo os cirurgiõesdentistas, auxiliares e os estudantes estão expostos rotineiramente aos principais materiais biológicos de grande potencial de contaminação, configurando-se então, a importância do conhecimento e informação desses profissionais quanto às formas de proteção contra hepatite $\mathrm{B}$, conscientizando-os sobre a necessidade de manter sua integridade, bem como a do paciente (LOKESH et al., 2014; SANTOS et al., 2011).

A discussão sobre a vacinação contra a hepatite B é constante nos estudos internacionais, visto que altas prevalências são visíveis no campo da saúde, principalmente a odontológica. Essa problemática é embasada no referencial teórico sobre a necessidade da imunização contra o vírus VHB a partir da compreensão sobre as consequências à saúde desses profissionais que negligenciam a dose vacinal (MOMENI et al., 2014; KUMAR et al., 2015). A vacinação contra a hepatite B torna-se uma grande aliada na preservação da saúde do indivíduo, visto que é a forma mais eficaz de amplo acesso e cobertura populacional, principalmente daqueles que estão em contato direto com fluídos corporais, sangue e materiais cortantes (REZENDE et al., 2010).

$\mathrm{O}$ acidente ocupacional na área da saúde é um dos principais meios de infecção a hepatite $\mathrm{B}$, visto a susceptibilidade dos materiais contaminados, sangue e fluídos corporais entrarem em contato com lesões percutâneas ou pele não íntegra daqueles profissionais que estão clinicando (MARTINS et al., 2015). Portanto, a utilização dos equipamentos de proteção individual (EPI), a higienização das mãos, a confirmação da imunização, descarte correto dos materiais perfuro-cortantes e a atenção à atividade clínica realizada, devem ser incentivados e ressaltados, pois correspondem a medidas básicas de proteção à saúde do profissional na prevenção e minimização dos acidentes laborais (ANDRADE et al., 2013; SANTOS et al., 2014).

Com o intuito de reduzir a disseminação da hepatite B entre os profissionais da odontologia é de grande importância o debate sobre esse tema na formação acadêmica, posto que as condutas nas práticas clínicas são decorrentes da sua percepção ao referencial obtido. Com base nisso, o objetivo desse estudo foi avaliar a conduta dos acadêmicos frente ao protocolo de vacinação contra hepatite B e sua atitude pós-acidentes perfuro-cortantes.

\section{METODOLOGIA}

Trata-se de um estudo de corte transversal descritivo quantitativo, realizado em uma universidade pública do noroeste paulista. Foram convidados para participar da pesquisa todos os alunos que cursavam o $3^{\circ}, 4^{\circ}$ e $5^{\circ}$ ano $(n=193)$, que já desenvolviam atividades clínicas nas disciplinas cursadas. Foram excluídos do estudo os alunos dos dois primeiros anos que apresentam apenas atividades teóricas na grade curricular e os que não estavam presentes no dia da aplicação do questionário.

O instrumento utilizado para coleta dos dados foi do tipo inquérito semiestruturado autoaplicável, com questões elaboradas que versavam sobre o esquema vacinal contra a hepatite B e a conduta dos alunos sobre 
os acidentes perfuro-cortantes. A condução do estudo em campo foi realizada por apenas um pesquisador previamente calibrado sobre o assunto. Foi apresentado aos participantes da pesquisa o Termo de Consentimento Livre e Esclarecido, de acordo com os critérios exigidos na Resolução 466/12 sobre pesquisas com seres humanos.

Os dados coletados foram digitados e tabulados com o auxílio do software Epi Info 7.1, e o processamento foi feito pela estatística descritiva por meio da distribuição de frequências absolutas e percentuais.

O presente estudo teve aprovação pelo comitê de ética em pesquisa da Faculdade de Odontologia de Araçatuba (SP), processo $\mathrm{n}^{\mathrm{O}} 632.067$.

\section{RESULTADOS E DISCUSSÃO}

Do total dos participantes, $67 \%$ correspondiam ao sexo feminino e $33 \%$ ao sexo masculino, a média da idade foi de 21,6 anos (DP $=1,4$ e mediana $=21$ ) $\mathrm{e}$ $40,52 \%$ dos mesmos estavam de 1 a 2 anos em práticas clínicas.

Ao serem questionados sobre o conhecimento do tema hepatite B, $94,77 \%$ dos entrevistados afirmaram à interrogativa, sendo que desse percentual total, $96,55 \%$ obtiveram a informação dentro de sala de aula. Em relação ao fator etiológico da hepatite B, 32,1\% dos alunos não acertaram ou não responderam a questão (Tabela 1). No que se refere à vacinação contra $\theta$ hepatite B, 92,16\% dos alunos afirmaram ter sido imunizados com as três doses da vacina, entretanto, $73,1 \%$ destes não fizeram o exame anti-HBS (Figura-1). Quanto ao resultado da soroconversão do anti-HBS, dos 38 indivíduos que realizaram o exame, $52,6 \%$ estavam de fato imunes conforme dito pelos voluntários do estudo. Quando indagados sobre o conhecimento dos participantes em relação ao significado do resultado do exame anti-HBS, 41,18\% disseram ter conhecimento, sendo que desse total, 19,05\% não acertaram a sua interpretação.
Tabela 1. Distribuição absoluta e percentual do perfil e conhecimento dos acadêmicos sobre a hepatite $\mathrm{B}$

\begin{tabular}{llcc}
\hline Variáveis & & n & \% \\
\hline Sexo & Feminino & 103 & 67,3 \\
& Masculino & 50 & 32,7 \\
\hline Tempo de atividade clínica & $<1$ ano & 17 & 11,1 \\
& $1 \mid---2$ anos & 62 & 40,5 \\
& $2 \mid---3$ anos & 55 & 36,0 \\
& $>3$ anos & 19 & 12,4 \\
\hline $\begin{array}{l}\text { Tem algum conhecimento } \\
\text { sobre o tema hepatite B? }\end{array}$ & Sim & 145 & 94,8 \\
& Não & 8 & 5,2 \\
\hline **Onde recebeu as & Sala de aula & 140 & 96,5 \\
informaçóes? & Mídias (TV, & 5 & 3,5 \\
& $\begin{array}{l}\text { Internet, } \\
\text { jornal) }\end{array}$ & & \\
\hline $\begin{array}{l}\text { Qual o fator etiológico da } \\
\text { hepatite B? }\end{array}$ & Vírus & 104 & 67,9 \\
& Bactéria & 20 & 13,1 \\
& Outros & 29 & 19,0 \\
\hline
\end{tabular}

** Questão destinada àqueles que afirmaram ter conhecimento sobre o tema hepatite B.

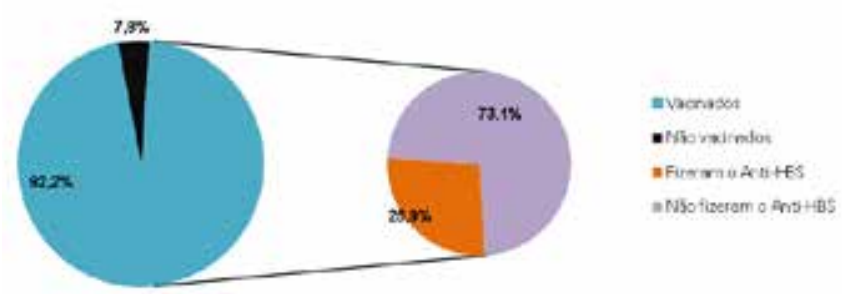

Figura 1. Distribuição percentual dos graduandos que tomaram a vacina contra a hepatite B e que fizeram o exame anti-HBS

O conhecimento dos futuros cirurgiões-dentistas sobre a hepatite B é dimensionado como uma ferramenta para minimizar as principais formas de transmissibilidade e infectividade do vírus nos consultórios odontológicos. Essa concepção do profissional é fundamental, pois a partir da problematização exposta sobre os grandes agravos à saúde, geram-se estratégias e medidas eficazes para interromper a disseminação do vírus, assim como garantir a manutenção da sua saúde e a integridade física (ALAVIAN et al., 2011). Em um estudo realizado com cirurgiões-dentistas do Oriente Médio, foi relatado que a maioria dos participantes do estudo tinha um conhecimento pleno sobre as formas de infecção e as consequências adquiridas com a doença. Assim sendo, 
observou-se que os cirurgiões-dentistas apresentaram uma grande preocupação em relação à contaminação com VHB e conscientemente afirmaram que a prevenção e o controle são os principais métodos para evitar a hepatite B (AL-HAZMI et al., 2015).

No presente estudo, verificou-se que do total de participantes, apenas $24,8 \%$ fizeram o teste de soroconversão, sendo que desta unidade amostral, apenas $13,07 \%$ estavam imunes contra o VHB, conforme o exame anti-HBS dito positivo pelo entrevistado. Os dados dessa pesquisa, quanto à realização do teste de soroconversão, estão entre as prevalências evidenciadas na literatura, variando de $5,6 \%$ a $47,9 \%$. As diferenças entre as estatísticas encontradas estão relacionadas ao apelo político-cultural entre os países e regiões onde foram conduzidos os estudos, dada a importância em que a vacinação, bem como a verificação da imunização é preconizada. Assim sendo, a discussão sobre a importância da cobertura vacinal, como um ato de responsabilização profissional é de grande importância para a conscientização do autocuidado em saúde (SACCHETTO et al., 2013; ALAVIAN et al., 2011).

O quadro epidemiológico apresentado retrata a falta de conhecimento e a negligência dos futuros profissionais da saúde quanto à principal forma de prevenção da inflamação hepática, assim como na preservação da sua própria saúde. Em virtude disto, a conscientização sobre a importância da vacinação e confirmação da mesma é fundamental em dimensões epidemiológicas, pois uma vez controlada e minimizada a prevalência de portadores crônicos da doença, a redução das taxas de incidência serão significativas no controle da hepatite no contexto coletivo (FERREIRA et al., 2012).

De modo geral, a cobertura vacinal entre os cirurgiões-dentistas ainda tem se mostrado falha nos dias atuais, mesmo sendo disponibilizadas gratuitamente desde 1982 e recomendada a todos os profissionais da saúde no início dos anos 90 (RESENDE et al., 2010). Sabese que a vacina contra a hepatite $\mathrm{B}$, em casos particulares, pode apresentar algumas manifestações orais como líquen plano e reação liquenóide, e complicações sistêmicas como púrpura trombocitopênica idiopática, lúpus eritematoso e doenças neuromusculares, esses casos são agravados principalmente se o indivíduo já estiver apresentando indícios de uma doença autoimune. Em virtude disto, aqueles que apresentam complicações sistêmicas ou que necessitam de precauções às doses da vacina, as recomendações devem ser esclarecidas e a situação médica deve ser acompanhada. Entretanto, na ótica coletiva, a vacina contra a hepatite B supera as implicações negativas e as reações adversas da mesma, visto que é uma doença pandêmica na qual pode culminar em estado de morbidade hepática e em alguns casos levando ao óbito (TARAKJI et al., 2014).

$\mathrm{Na}$ análise dos resultados do estudo, no que se refere aos acidentes com perfurocortantes, observou-se que $18,3 \%$ do total dos indivíduos do estudo já tinham se ferido com estes materiais, sendo que deste percentual, $64,3 \%$ seguiram o protocolo para esse tipo de acidente e apenas $28,6 \%$ realizaram os exames com a frequência recomendada (Tabela 2). Os materiais mais frequentes nestes acidentes foram as agulhas da seringa carpule (57\%) e as agulhas dos fios de sutura (14\%) (Figura 2).

Tabela 2. Distribuição absoluta e percentual da atitude dos acadêmicos, em casos de acidentes com perfuro-cortantes

\begin{tabular}{|c|c|c|c|c|}
\hline \multirow{2}{*}{ Variáveis } & \multicolumn{2}{|c|}{ Sim } & \multicolumn{2}{|c|}{ Não } \\
\hline & f & $\%$ & f & $\%$ \\
\hline $\begin{array}{l}\text { Já teve algum acidente dom } \\
\text { perfuro-cortante? }\end{array}$ & 28 & 18,3 & 125 & 81,7 \\
\hline $\begin{array}{l}\text { **Conhece o protocolo para } \\
\text { acidentes com perfuro-cortantes? }\end{array}$ & 25 & 89,3 & 3 & 10,7 \\
\hline $\begin{array}{l}* * \text { Seguiu o protocolo com } \\
\text { perfuro-cortantes? }\end{array}$ & 18 & 64,3 & 10 & 35,7 \\
\hline$* * O$ paciente fez os exames? & 12 & 42,9 & 16 & 57,1 \\
\hline **Tomou o coquetel? & 2 & 7,2 & 26 & 92,8 \\
\hline $\begin{array}{l}\text { **Após o acidente fez os exames } \\
\text { com a frequência recomendada? }\end{array}$ & 8 & 28,6 & 20 & 71,4 \\
\hline
\end{tabular}

** Questões destinadas aos indivíduos que já se perfuraram.

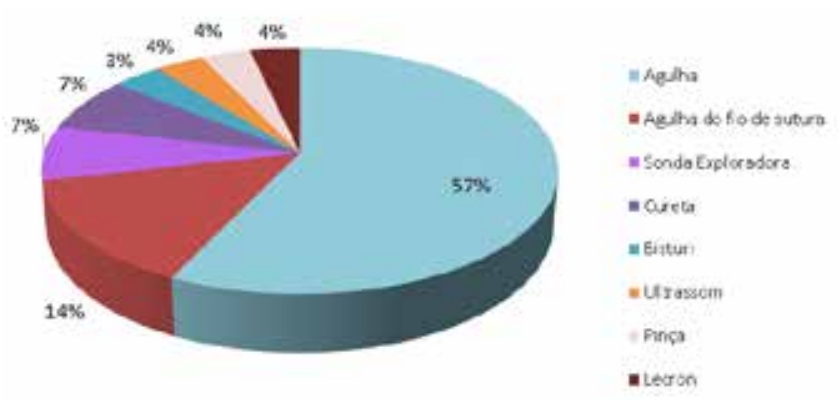

Figura 2. Distribuição percentual dos principais materiais e instrumentais envolvidos nos acidentes perfuro-cortantes 
Os profissionais da Odontologia estão frequentemente sujeitos a acidentes com algum tipo de material ou instrumental perfuro-cortante, devido sua competência clínica ter um campo de visão restrito e inerente aos movimentos indesejados dos pacientes. Da mesma forma ocorre em relação à infecção e à contaminação do profissional que sofre a lesão, visto que os cirurgiões-dentistas estão expostos às principais fontes de disseminação de patógenos oriundos dos fluídos biológicos, como sangue e saliva (GARCIA et al., 2008).

A medida mais eficaz para diminuir o risco de infecção com os materiais biológicos é prevenir os acidentes ocupacionais, entretanto, mesmo com o profissional utilizando todos os Equipamentos de Proteção Individual (EPI), em caso de alguma lesão perfuro-cortante, todos estes estarão sujeitos a riscos de contaminação, sendo então considerado um caso de urgência médica (MARTINS, 2011). Com base nos dados do estudo em questão, 64,3\% dos acidentados seguiram o protocolo recomendado em procurar o serviço médico especializado, divergindo do achados em outros estudos, que apresentaram uma prevalência de 13,2\% a 76,6\% (ORESTES-CARDOSO et al., 2009; GARBIN et al., 2011).

$\mathrm{O}$ correto acondicionamento e descarte dos resíduos de serviços de saúde, incluindo os perfurocortantes, devem ser realizados de forma adequada e segura a fim de evitar futuros acidentes a partir de uma conduta imprudente. Essa consideração deve ser pautada nas instituições de ensino superior, visto que o desconhecimento sobre a forma correta de descarte de insumos odontológicos contaminados é uma realidade brasileira, sendo a agulha da carpule um dos principais causadores de lesões percutâneas nesses indivíduos (GARBIN et al., 2015).

Observou-se neste estudo que as condutas necessárias a serem tomadas em relação ao autocuidado dos acidentados foram negligenciadas por aqueles que se perfuraram, pois houve uma pequena porcentagem de profissionais que realizaram os exames $(28,6 \%)$ com a frequência recomendada. Dados esses que corroboram com os estudos de Andrade et al. (2013) e Martins et al (2010), que demostraram, respectivamente, as mesmas desapropriações no autocuidado pós-exposição aos acidentes com perfuro-cortantes ao negligenciarem a realização dos exames recomendados (38\%) e (28,4\%) (ANDRADE et al., 2013; MARTINS et al., 2010).

\section{CONCLUSÃO}

Conclui-se que as condutas e atitudes dos acadêmicos sobre a hepatite $B$ ainda apresentam falhas, pois apenas uma pequena quantidade dos entrevistados seguiu o protocolo vacinal com a verificação da soroconversão anti-HBS. Da mesma maneira, observouse nas condutas pós-acidentes com perfuro-cortantes, pois a minoria realizou a quimioprofilaxia e os exames com a frequência recomendada.

\section{REFERÊNCIAS}

ALAVIAN, S. M.; MAHBOOBI, N.; MAHBOOBI, N.; SAVADRUDBARI, M. M.; AZAR, P. S.; DANESHVAR, S. Iranian dental student's knowledge of hepatitis B virus infection and its control practices. J Dent Educ., v. 75, n. 12, p. 1627-34, dec. 2011.

AL-HAZMI, A. H. Knowledge, attitudes and practice of dentists concerning the occupational risks of hepatitis B virus in Al Jouf Province, Saudi Arabia. Niger J Clin Pract., v. 18, n. 2, p. 276-281, mar./apr. 2015.

ANDRADE NETO, E. P.; DUTRA, C. S.; LIMA, V.; GOES, P. Prevalência de acidentes ocupacionais e perfil de vacinação contra Hepatite B entre estudantes e profissionais da odontologia: um estudo piloto. Arq Odontol., v. 49, n. 1, p. 32-38, mar. 2013.

BABINSKI, C. E.; NUNES, E. M. A.; LOCATELLI, R.; JUNIOR, S. E. M. Prevalência de infecção pelo vírus da hepatite $\mathrm{A}$, hepatite $\mathrm{B}$ e hepatite $\mathrm{C}$, no município de Maringá, Norte do Paraná, no período de 2001 a 2004. Saude e Pesqui.,v. 1, n. 2, p. 117-124. 2008.

BRASIL. Ministério da Saúde. Secretaria de políticas de saúde coordenação nacional de DST, Aids e Hepatites Virais. ABCDE Diagnóstico para Hepatites Virais. Brasília: Ministério da Saúde, 2009.

BRASIL. Ministério da Saúde. Secretaria de vigilância de saúde. Departamento de DST, Aids e Hepatites Virais. Protocolo Clínico e Diretrizes Terapêuticas para Prevenção da Transmissão Vertical de HIV, Sífilis e Hepatites Virais. Brasília: Ministério da Saúde, 2015.

BROZOSKI, M. A.; TRAINA, A. A.; NACLÉRIO-HOMEM, M. 
D. G.; DEBONI, M. C. Z. Ocorrência de acidentes pérfurocortantes em um curso de odontologia. Rev gauch odontol., v. 58, n. 1, p. 77-80. 2010.

FERREIRA, R. C.; GUIMARÃES, A. L. S.; PEREIRA, R. D.; ANDRADE, R. M.; XAVIER, R. P.; MARTINS, A. M. E. D. B. Vacinação contra hepatite B e fatores associados entre cirurgiões-dentistas. Rev Bras Epidemiol., v. 15, n. 2, p. 315-323. 2012.

GARBIN, A. J. I.; WAKAYAMA, B.; TERUEL, G. P.; GARBIN, C. A. S. A visão dos acadêmicos de odontologia sobre o gerenciamento dos resíduos do serviço de saúde. Arch Health Invest., v. 4, n. 4, p. 63-67. 2015.

GARBIN, C. A. S.; MARTINS, R. J.; GARBIN, A. J. I.; HIDALGO, L. R. C. Conductas de estudiantes del área de la salud frente a la exposición ocupacional a material biológico. Cienc Trab., v. 11, n. 31, p. 19-21. 2009.

GARCIA, L. P.; BLANK, V. L. G. Condutas pós-exposição ocupacional a material biológico na odontologia. Rev Saúde Pública., v. 42, n. 2, p. 279-286. 2008.

KUMAR, S.; BASAK, D.; KUMAR, A.; DASAR, P.; MISHRA, P.; KUMAR, A.; KUMAR SINGH, S.; DEBNATH, N.; GUPTA, A. Occupational Hepatitis B Exposure: Peek into Indian Dental Students' Knowledge, Opinion, and Preventive Practices. Interdiscip Perspect Infect Dis., v. 2015, Article ID 190174,. doi:10.1155/2015/190174

LOKESH, U.; SRINIDHI, D.; REDDY, K. S. Post exposure prophylaxis to occupational injuries for general dentist. J Indian Prosthodont Soc., v. 14, sup 1, p. 1-3, 2014.

MARTINS, A. M. E. B. L.; PEREIRA, R. D.; FERREIRA, R. C. Adesão a protocolo pós-exposição ocupacional de acidentes entre cirurgiões dentistas. Rev. Saúde Pública., v. 44, n. 3, p. 528-540. 2010.

MARTINS, R. J.; GARBIN, C. A. S.; GARBIN, A. J. I.; PRIETO, A. K. C. Conhecimento e atitudes de profissionais da saúde frente à exposição ocupacional a material biológico. Cienc Trab., v. 13, n. 40, p. 113-115. 2011.

MARTINS, R. J.; MOIMAZ, S. A. S.; SUNDEFELD, M. L. M. M.; GARBIN, A. J. I.; GONÇAVES, P. R. V.; GARBIN, C. A. S. Adesão às precauções padrão sob o prisma do Modelo de Crenças em Saúde: a prática de reencapar agulhas. Ciênc
Saúde Coletiva., v. 20, n. 1, p. 193-198, jan. 2015.

MOMENI, N.; AHMAD AKHOUNDI, M. S.; ALAVIAN, S. M.; SHAMSHIRI, A. R.; NOROUZI, M.; MAHBOOBI, N.; MOOSAVI, N.; JAZAYERI, S. M. HBV vaccination status and response to hepatitis B vaccine among Iranian dentists, correlation with risk factors and preventive measures. Hepat Mon., v. 15, n. 1, dec. 2014.

ORESTES-CARDOSO, S. M.; FARIAS, A. B. L.; GUERRA, M. R. M.; ORESTES-CARDOSO, A. J.; JUNIOR, I. D. F. C. Rev. bras. Saúde ocup., v. 34, n. 119, p. 06-14. 2009.

RESENDE, V. L. S.; ABREU, M. H. N. G.; TEIXIERA, R.; PORDEUS, I. A. Hepatites Virais na Prática Odontológica: Riscos e Prevenção. Pesq Bras Odontoped Clin Integr, João Pessoa, v. 10, n. 2, p. 317-388, mai./ago. 2010.

SACCHETTO, M. S.; BARROS, S. S.; ARARIPE, T. A.; SILVA, A. M.; FAUSTINO, S. K.; SILVA, J. M. Hepatitis: knowledge, vaccine situation and seroconversion of dentistry students of a public university. Hepat Mon., v. 13, n. 10. 2013.

SANTOS, A. A. B. D.; SOARES, I. M. S.; LIMEIRA, I. A.; ÂNGElO, A. R.; VElOSO, H. H. P.; QUEIROGA, A. S. Conhecimentos e comportamentos de risco dos alunos de odontologia do Centro Universitário de João Pessoa em relação à Hepatite B. Comun Ciências Saúde., v. 22, n. 4, p. 335-342. 2011.

SANTOS, J. A. D.; COSTA, F. M. Hepatite B: fatores de risco e atitudes profiláticas de estudantes e profissionais da saúde. Saude e Pesqui, v. 7, n. 2, p. 341-351, maio./ ago. 2014.

TARAKJI, B.; ASHOK, N.; ALAKEEL, R.; AZZEGHAIBI, S.; UMAIR, A.; DARWISH, S.; ELKHATAT, E. Hepatitis B Vaccination and Associated Oral Manifestations: A NonSystematic Review of Literature and Case Reports. Ann Med Health Sci Res., v. 4, n. 6, p. 829-836. 2014.

WHO. WORLD HEALTH ORGANIZATION. Guidelines for the prevention, care and treatment of persons with chronic hepatitis b infection. WHO, 2015.

Recebido em: 12 de janeiro de 2016 Versão final recebida em: 27 de maio de 2016 Aceito em: 29 de maio de 2016 